ICH 2019

International Conference on Humanities

\title{
STUDY ON ECONOMIC-ECOLOGICAL RESILIENCE MEASUREMENT AND IMPROVEMENT STRATEGY OF YUNNAN ETHNIC REGIONS
}

\author{
Ruiliang Li (a), Yan Li (b)*, Jie Shen (c), Chao Fu (d), Chunhong Xia (e), Zhangfeixue Li (f) \\ *Corresponding author
}

(a) Yunnan University, No.2 North Cuihu Road, Wuhua District, Kunming, China, LRL6610@163.com

(b) Yunnan University, No.2 North Cuihu Road, Wuhua District, Kunming, China, Leeyan5@163.com

(c) Yunnan University, No.2 North Cuihu Road, Wuhua District, Kunming, China, 951341231@qq.com

(d) Yunnan University, No.2 North Cuihu Road, Wuhua District, Kunming, China, 642007090@qq.com

(e) Yunnan University, No.2 North Cuihu Road, Wuhua District, Kunming, China, RitaXCH@163.com

(f) Yunnan University, No.2 North Cuihu Road, Wuhua District, Kunming, China, 1033927107@qq.com

\begin{abstract}
Nowadays, the ecological environment has been seriously damaged due to the continuous development of social economy and the rapid advancement of urbanization. The construction of ecological civilization has become the focus of common concern of all sectors of society. Yunnan ethnic minority areas are mostly distributed in ecological fragile areas, facing the threat of natural disasters, such as earthquakes and mudslides, and their economic development is also relatively backward. Therefore, using the coordinated development model, this paper takes 8 ethnic minority areas in Yunnan Province as the research object to measure it's economic and ecological resilience and the coordination between them. Results prove that: First, the economic resilience and ecological resilience of Yunnan ethnic areas have significantly improved, but the level is still to be improved; Second, there is a huge gap of economic and ecological resilience among regions; Third, the coordinated degree of regional economic and ecological resilience showed a good trend of stable, and constantly coordinated development. Finally, this paper proposes specific strategies to promote the resilience of ethnic regions from the perspective of economy, ecology and the coordination relationship between them, in order to achieve a "win-win" economic development and ecological security in ethnic areas.
\end{abstract}




\section{Introduction}

The regional coordinated and sustainable development becomes the major issue related to the national economy and people's livelihood (Cai et al., 2012). However, with the rapid development of the economy and the issue of climate change, the regional economic and ecological security problems have increasingly led to increased regional vulnerability ( $\mathrm{Xu}$ et al., 2014). Faced with the increasingly deteriorating ecological environment caused by economic growth at the expense of environment, how to promote the regional economic development while protecting the ecological environment, so as to promote the sustainable development between them? As a new research paradigm, the concept of "resilience" has attracted extensive attention in the academic and practical circles.

"Resilience" is a term that derived from the Latin "resilio", which means "return to the original state" (Alexander, 2013). With the in-depth integration of the concept of resilience and city, the resilient city becomes a new theoretical approach to urban governance. In terms of the definition resilient city, Resilience Alliance defines it as the ability of an urban system to digest and absorb external disturbances and maintain the original main features, structures and key functions. As the part of resilient system, “economic resilience" and "ecological resilience" have gradually attracted the attention of scholars. In the beginning, scholars focused on the concept of economic and ecological resilience. Hill (2012) defines economic resilience as "the ability of regional system to respond to unpredictable economic crisis and return to original equilibrium". Man (2019) asserts that economic resilience is the ability of economic system to maintain long-term economic development in the face of periodic economic crisis and technological change. In terms of "ecological resilience": Holling (1973) defines it as "the ability of ecosystem to absorb changes, sustain and restore balance after a short shock". Pimm (1984) studied the ecological resilience system, he believed that an ecological resilience system includes 4 parts: the range from the equilibrium state to the state of loss resilience (latitude), the ability resistance to external disturbance to keep the system in equilibrium (resistance), the critical value of system close to collapse (precariousness) and association of group hierarchies within a disturbed system (panarchy). China scholars such as Chen and Li (2017) emphasized that ecological resilience negated the single and stable equilibrium state in the engineering resilience theory, and advocated multiple equilibrium states.

With the deepening of the research, relevant scholars and organizations have carried out research on the measurement of the economic and ecological resilience, but there is no unified evaluation or standard in the academic field so far. Rockefeller foundation proposed to build resilience evaluation system through health and well-being, social economy, urban system and its service and leadership strategy. According to the concept of resilience, Liu and Zeng (2014) constructed a comprehensive evaluation system including ecological resilience, economic resilience, engineering resilience and social resilience. Sun et al. (2017) selected indicators from four aspects of ecological environment, municipal facilities, economy and society to make resilience measures for 16 prefecture-level cities in the Yangtze River Delta region.

In order to promote the sustainable development of the socio-economic, it is essential to introduce the concept of "resilience" into regional development. The relevant researches of domestic and foreign scholars have made useful explorations for regional coordinated development, but there are few studies on economic and ecological resilience in ethnic areas. Therefore, on the basis of constructing the 
evaluation index system of economic and ecological resilience, this paper takes 8 minority areas in Yunnan Province as the research object, measures the value of economic and ecological resilience in minority areas and analyses the coordination relationship and types between them, and proposes strategic suggestions for regional sustainable development.

\section{Problem Statement}

\subsection{Uncertainty in regional socio-economic development}

Sustainable development is a global topic. With the economic globalization and the development of information technology, regional socio-economic development is facing more and more uncertain disturbances. As far as Yunnan minority areas are concerned, first of all, natural disasters occur frequently and it is characterized by multiple types, wide distribution, high frequency and heavy loss (Nie, 2017). It is a typical natural disaster frequent area, and multiple natural disasters have become a major threat to the socio-economic development of ethnic areas. Secondly, the terrain of Yunnan ethnic regions is complex, the traffic is in inconvenient for a long time, and the economy is lag behind other cities. Finally, ethnic minority areas in Yunnan Province are mostly distributed in alpine and karst areas. The natural environment is diverse, the types of geological features are complex, and the ecological environment is fragile. The "inconsistent conditions" of the special geographical environment and the fragile ecological environment are combined with frequent disasters, which pose serious threats to the sustainable development of Yunnan ethnic regions. Faced with the dual dilemma of "insufficient innate conditions and poor subsequent development", ethnic minority areas are forced to accelerate the construction of resilient economic and ecological practices, and constantly enhance the region's resilience ability, so as to promote the quality development of the region.

\subsection{The imbalance development between urbanization and ecology}

"Urbanization is the necessary road of China's modernization construction." Indeed, the rapid advancement of urbanization has played an important role in scientific and technological innovation, industrial transformation and the improvement of people's living standards. And the continuous improvement of urbanization rate has also made cities become the most dynamic core areas of China's economic development pattern, as well as the growth pole and core fulcrum of China's productivity layout. On the other hand, in the process of urbanization development, it is inevitable to cause many ecological problems, such as air pollution and resource shortage (Liu \& Zhao, 2019; Zhou, 2019). The ecological environment has been destroyed and then the imbalance development between urbanization and ecology. At the same time, promoting urbanization at the expense of the environment is unsustainable, and the cost of late ecological environment restoration is very high. Therefore, how to promote the coordinated and sustainable development between urbanization and ecological environment is an urgent problem to be solved. 


\section{Research Questions}

\subsection{What is ecological resilience and economic resilience?}

As a new perspective and theoretical system, the idea of "resilience" has become a research hotspot for scholars at domestic and abroad. However, its theoretical framework has not yet been unified. Therefore, this paper will combine the existing research results to define the concept of ecological resilience and economic resilience. Ecological resilience: the capacity of ecosystem to restore and improve the function under the guidance of human activities and to improve the level of ecological resilience or achieve a new balance. Economic resilience: the ability of a regional economic system to maintain stable economic development or to promote new developmental trends after accepting and eliminating uncertainty. Based on the concept of economic and ecological resilience, the evaluation index system is constructed, and the resilience of Yunnan minority areas is quantitatively measured.

\subsection{How to establish the evaluation index system for ecological and economic resilience in ethnic areas?}

On the basis of defining the concepts of ecological resilience and economic resilience, this paper establishes an index evaluation system based on the background of prominent ecological environmental security problems and backward regional economic development in Yunnan ethnic minority areas.

\subsection{How to explore the coordination relationship between ecological resilience and economic resilience?}

In this context, by exploring the degree and regional differences of coordinated development of ecology and economy, we can find the weak links in the process of economic and social development in Yunnan minority areas, and promote the process of ecological civilization and the sustainable development of regional economy.

\section{Purpose of the Study}

On the basis of combing the relevant literature, combining the concept of economic and ecological resilience with the actual situation of the geographical location, natural resources and socio-economic development level of Yunnan minority areas, this paper constructs an evaluation index system for evaluating the economic and ecological resilience of Yunnan minority areas, so as to measure their economic resilience and ecological resilience, and analyse the coordination between them. Finally, in view of the actual situation, the paper puts forward the strategies and measures to enhance regional resilience from three aspects of economy, ecology and their relationship. On the basis of exploring the new urbanization path in ethnic areas, it provides a research model for the future construction of "economic-ecological resilience" coordination in ethnic minority areas of China, even in South Asia and Southeast Asia. 


\section{Research Methods}

\subsection{Coordinated development mode}

\subsubsection{Data standardization}

The original indicators have different effects on ecological resilience, it is necessary to standardize the data before assigning weights to the selected index. In this paper, the vector gauge method (Tong, 2013 ) is adopted to deal with the indexes with different properties. The formula is as follows:

$$
X_{\mathrm{ij}}^{*}=\frac{X_{i j}}{\sqrt{\sum_{\mathrm{i}=1}^{\mathrm{n}}\left(\mathrm{x}_{i j}^{2}\right)}}
$$

$X^{*}$ is the normalized index value; $X$ is the original value.

\subsubsection{Determine the index weight}

This paper uses the entropy method to determine the weights of the selected indicators, the specific calculation steps are as follows:

(1) Determine the information entropy increase

Calculate the proportion $P_{i j}$ of the index value of the $\mathrm{i}$-th year under the $\mathrm{j}$-th indicator, and the formula is as follows:

$$
P_{\mathrm{ij}}=\frac{X_{i j}^{*}}{\sum_{\mathrm{i}=1}^{n} X_{i j}^{*}}
$$

According to the definition of entropy, the information entropy value e of the $\mathrm{j}$-th index is calculated by formula (3)

$$
e_{j}=-k \sum_{i=1}^{n} P_{i j} \cdot \ln p_{i j}
$$

(2) Determine the information utility value, the formula is $d_{j}=1-e_{j}$

(3) Determine the index weight

$$
a_{j}=\frac{d_{j}}{\sum_{j=1}^{m} d_{j}}
$$

\subsubsection{Economic and ecological resilience value}

The economic resilience $\mathrm{f}(\mathrm{x})$ and ecological resilience $\mathrm{g}(\mathrm{y})$ were calculated by formulas (6) and (7) respectively.

$$
f(x)=\sum_{j=1}^{m} a_{j} x_{j}^{*} \quad(6) \quad g(y)=\sum_{j=1}^{m} b_{j} y_{j}^{*}
$$

Among them, the number of indicators is $j(=1,2, \cdots, m) ; X^{*}, Y^{*}$ are the standard values of economic and ecological resilience after standardization has remained; $a_{j}$ means the weight of indicators 
of economic resilience, and $\sum a_{j}=1 ; b_{j}$ represents the weight of indicators of ecological resilience, and $\sum b_{j}=1$

\subsubsection{Analyse the coordination relationship}

(1) Calculate the degree of development

Using the degree of development $(\mathrm{T})$ to measure the level of economic and ecological resilience. Its calculation formula is as follows:

$$
T=\alpha f(x)+\beta g(y)
$$

$\alpha, \beta$ is the undetermined coefficient and $\alpha+\beta=1$. This paper considers that economic resilience is as important as ecological resilience, so $\alpha=\beta=0.5$.

(2) Calculate the coupling coordination degree

The term of "coupling coordination" reflects the interaction of two or more systems under their own and external influences. The economy and ecology of the region are interdependent. Therefore, the coupling coordination model can be used to analyse the coordination relationship between economic and ecological resilience. Its calculation formula is as follows:

$$
C=\left\{f(x) * g(y) /\left[\frac{f(x)+g(y)}{2}\right]^{2}\right\}^{\theta}
$$

$\theta$ is the adjustment factor, usually $2 \leq \theta \leq 5$, this paper takes $\theta=2$; $C$ is the coupling value for them, the range: $C \in[0,1]$, the larger $\mathrm{C}$, the closer to 1 is, the more coordinated the two are; otherwise, the worse.

(3) Calculate the degree of coordinated development

Coordinated development degree (D) is a comprehensive evaluation index that measures the degree of coordinated development of economic resilience and ecological resilience and its development degree. Its calculation formula is as follows:

$$
D=\sqrt{C^{*} T}
$$

The value of $\mathrm{D}$ ranges from 0 to 1 , and the larger the $\mathrm{D}$ value, the closer to 1 , indicating that the coordinated development of them is better; otherwise, the worse.

\subsection{Establishing of evaluation index system for economic and ecological resilience}

Combined with the real circumstance of Yunnan ethnic regions, this paper sets up the evaluation index system to explore it on the basis of the concept of economic and ecological resilience. It divides into three levels: target layer, criteria layer and element layer. As shown in Table 01. 
Table 01. Economic and ecological resilience index system in Yunnan ethnic regions

\begin{tabular}{|c|c|c|c|c|}
\hline Target layer & Criteria layer & Element layer & Unit & Weight \\
\hline \multirow{14}{*}{$\begin{array}{l}\text { Evaluation Index } \\
\text { System of } \\
\text { Economic- } \\
\text { Ecological } \\
\text { Resilience in } \\
\text { Minority Areas of } \\
\text { Yunnan }\end{array}$} & \multirow{7}{*}{$\begin{array}{l}\text { Economic } \\
\text { resilience }\end{array}$} & Per capita GDP & yuan & 0.144532 \\
\hline & & $\begin{array}{l}\text { The proportion of secondary } \\
\text { and tertiary industries in GDP }\end{array}$ & $\%$ & 0.149342 \\
\hline & & Total fixed assets investment & 100 million yuans & 0.136808 \\
\hline & & Disposable income of residents & yuan & 0.145908 \\
\hline & & Foreign trade dependence value & 1 & 0.133911 \\
\hline & & $\begin{array}{l}\text { Total retail sales of consumer } \\
\text { goods }\end{array}$ & 100 million yuans & 0.143126 \\
\hline & & Urbanization rate & $\%$ & 0.146372 \\
\hline & \multirow{7}{*}{$\begin{array}{l}\text { Ecological } \\
\text { resilience }\end{array}$} & Total water resources & $\begin{array}{l}100 \text { million cubic } \\
\text { metres }\end{array}$ & 0.144373 \\
\hline & & Natural wetland area & 10,000 hectares & 0.14453 \\
\hline & & Arable land area & 10,000 hectares & 0.143899 \\
\hline & & Forest coverage & $\%$ & 0.145146 \\
\hline & & Per capita park green space area & $\begin{array}{c}\text { square } \\
\text { metre/person }\end{array}$ & 0.143897 \\
\hline & & Air quality index & $\begin{array}{l}\text { milligram/cubic } \\
\text { metre }\end{array}$ & 0.13367 \\
\hline & & Pesticide usage & 10 thousand tons & 0.144483 \\
\hline
\end{tabular}

\section{Findings}

\subsection{Calculation results of economic resilience in Yunnan ethnic regions}

After the data standardization and the weights of each index are determined, the economic resilience value of each year can be calculated by formula (6). As shown in Figure 01:

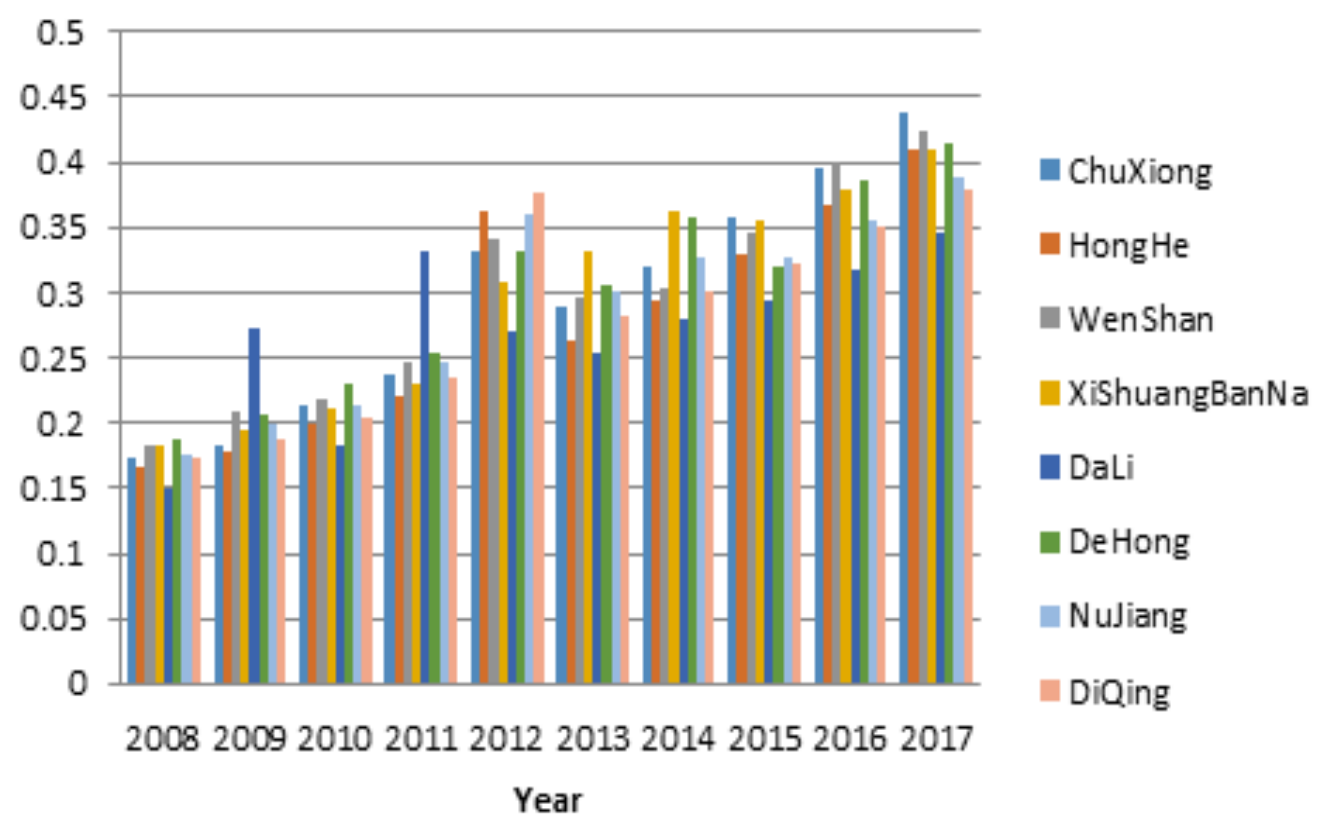

Figure 01. Statistical graph of economic resilience evaluation results of Yunnan ethnic regions 
Figure 01 shows that: (1) Overall, the economic resilience of Yunnan ethnic minority areas has shown a wave-like upward trend from 2008 to 2017. Compared with 2008, the economic resilience of the eight ethnic minority areas in 2017 significantly increased. Its due to the continuous optimization of economic structure, which makes the ability of minority areas to withstand economic risks has increased, and then their level of economic resilience continues to improve; (2) In 2012, the improvement of economic resilience of Yunnan ethnic regions is the most obvious in the first five years. Under the guidance of "Twelfth Five-Year Plan", Yunnan ethnic minority areas adhere to the theme of scientific development and the transformation of the model of economic development as the main line. (3) From 2008 to 2017, Chuxiong Yi Autonomous Prefecture has the largest improve range for economic resilience, that is, its economic resilience rises from low resilience (Zhang \& Feng, 2018) (2008: 0.174323) to moderate resilience (2017: 0.438907). For a long time, Chuxiong Prefecture has focused on improving economic quality and efficiency, and while maintaining stable economic growth, it has made good efforts to adjust its structure and promote reforms, so that its economic structure continue to be optimized and its economic quality significantly improved; (4) In sharp contrast, the economic resilience of the Dali Bai Autonomous Prefecture rose in wave in the past decade, but the range for improvement was the smallest.

The specific analysis shows that from the industrial structure, for many years, Dali relies mainly on the rich natural resources to develop tourism, and the tourism economy accounts for a large proportion. The single and unreasonable economic structure led to economic risks and lower economic resilience. Therefore, Dali Prefecture must continue to optimize and adjust the economic structure, reduce economic vulnerability and enhance economic resilience.

\subsection{Calculating results of ecological resilience in Yunnan minority areas}

Formula (7) is used to measure the ecological resilience of ethnic regions.

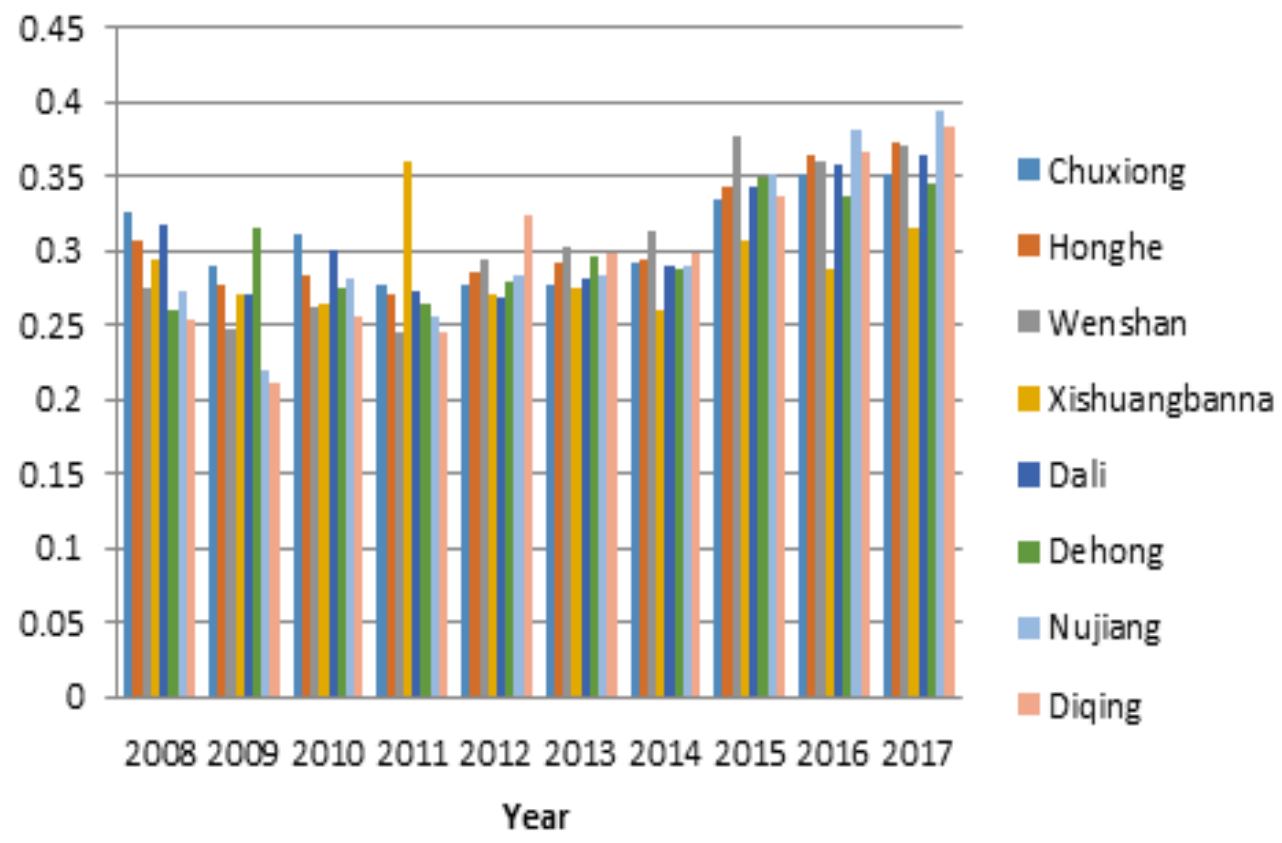

Figure 02. Statistical diagram of the results of assessment of ecological resilience in Yunnan ethnic areas 
It can be seen from Figure 02: (1) The ecological resilience of the eight minority areas has increased. In recent years, ethnic areas have thoroughly implemented the five development concepts, adhered to ecological priorities, and protected the environment to promote the construction of ecological civilization. Its ecological vulnerability has gradually decreased, and its ecological resilience level significantly increased; (2) From 2008 to 2017, the ecological resilience gap between different regions have remained. In 2013, the gap in ecological resilience among ethnic groups is the smallest, which indicated that the overall level of ecological resilience of Yunnan ethnic minority areas is good and the internal structure is reasonable; (3) Overall, the level of ecological resilience in Yunnan minority areas is low. From the average value of ecological resilience at the beginning of the study period $(0.263239)$ to 0.362485 in 2017 , it only increased by 0.099245 , the speed of increase was slow and the range for improvement was small. The specific analysis shows that the ecological environment in Yunnan minority areas is fragile, with low ecological carrying capacity and frequent natural disasters, resulting in low ecological resilience.

\subsection{Economic-Ecological resilience coordination measurement in Yunnan ethnic regions}

Based on the existing research $(\mathrm{Hu}, 2015)$, using the formula (6)-(10), the coordinated development degree of economic and ecological resilience of Yunnan ethnic minority areas can be calculated. However, due to the article space is limited, we only selected four-year data from 2008, 2011, 2014 and 2017 as samples (as shown in Table 02).

Table 02. Evaluation results of coordinated development of economic and ecological resilience in ethnic regions

\begin{tabular}{|c|c|c|c|c|c|c|c|c|}
\hline & & 2008 & & 2011 & & 014 & & 017 \\
\hline ChuXiong & 0.454201 & $\begin{array}{c}\text { Mild } \\
\text { maladjustment }\end{array}$ & 0.504957 & $\begin{array}{l}\text { On the verge } \\
\text { of imbalance }\end{array}$ & 0.552138 & $\begin{array}{l}\text { On the verge } \\
\text { of imbalance }\end{array}$ & 0.620693 & $\begin{array}{c}\text { Primary } \\
\text { coordinate }\end{array}$ \\
\hline WenShan & 0.459365 & $\begin{array}{c}\text { Mild } \\
\text { maladjustment }\end{array}$ & 0.495762 & $\begin{array}{c}\text { Mild } \\
\text { maladjustment }\end{array}$ & 0.55492 & $\begin{array}{l}\text { On the verge } \\
\text { of imbalance }\end{array}$ & 0.628153 & $\begin{array}{c}\text { Primary } \\
\text { coordinate }\end{array}$ \\
\hline $\begin{array}{c}\text { XiShuang } \\
\text { Banna }\end{array}$ & 0.461036 & $\begin{array}{c}\text { Mild } \\
\text { maladjustment }\end{array}$ & 0.517173 & $\begin{array}{l}\text { On the verge } \\
\text { of imbalance }\end{array}$ & 0.54306 & $\begin{array}{l}\text { On the verge } \\
\text { of imbalance }\end{array}$ & 0.592429 & $\begin{array}{l}\text { On the verge } \\
\text { of imbalance }\end{array}$ \\
\hline $\mathrm{DaLi}$ & 0.421904 & $\begin{array}{c}\text { Mild } \\
\text { maladjustment }\end{array}$ & 0.545387 & $\begin{array}{l}\text { On the verge } \\
\text { of imbalance }\end{array}$ & 0.533538 & $\begin{array}{l}\text { On the verge } \\
\text { of imbalance }\end{array}$ & 0.596214 & $\begin{array}{l}\text { On the verge } \\
\text { of imbalance }\end{array}$ \\
\hline NuJiang & 0.451302 & $\begin{array}{c}\text { Mild } \\
\text { maladjustment }\end{array}$ & 0.500766 & $\begin{array}{l}\text { On the verge } \\
\text { of imbalance }\end{array}$ & 0.55304 & $\begin{array}{l}\text { On the verge } \\
\text { of imbalance }\end{array}$ & 0.62575 & $\begin{array}{c}\text { Primary } \\
\text { coordinate }\end{array}$ \\
\hline DiQing & 0.445191 & $\begin{array}{c}\text { Mild } \\
\text { maladjustment }\end{array}$ & 0.489866 & $\begin{array}{c}\text { Mild } \\
\text { maladjustment }\end{array}$ & 0.547872 & $\begin{array}{l}\text { On the verge } \\
\text { of imbalance }\end{array}$ & 0.617562 & $\begin{array}{c}\text { Primary } \\
\text { coordinate }\end{array}$ \\
\hline
\end{tabular}

The results show that the economic and ecological resilience of six autonomous prefectures is changed from disorder to primary coordination during 2008-2017. During the research period, Xishuangbanna Dai Autonomous Prefecture and Dali Bai Autonomous Prefecture have been in a state of maladjustment and decline, but there are differences between them. 


\section{Conclusion}

The research found that: first, overall, the economic and ecological resilience of Yunnan ethnic minority areas have significantly improved, but the level is still to be improved. Secondly, there is a huge gap of economic and ecological resilience among regions. Thirdly, the coordination between economic and ecological resilience in ethnic regions shows a good trend of coordinated development.

Based on the above basic conclusions, this paper puts forward the following suggestions:

Firstly, we need to transform the way of economic growth and raise the quality of economic development. Yunnan ethnic minority areas must adhere to the quality and benefit first, take the supplyside structural reform as the main line, change the economic development model, promote the reform of economic development quality, optimizing the economic structure and improving the efficiency.

Secondly, we should maintain harmonious coexistence between human and nature, and accelerate the development of an ecological security pattern. Yunnan ethnic regions must defined on the basis of the ecological environment protection line in science, improve the ecological environment protection planning, implementation, patrol inspection system, to ensure that a high cost of illegal construction and implement of the ecological security barrier in ethnic regions.

Finally, coordinate the relationship between economic development and ecological environmental protection, and take the road of ecological civilization construction in ethnic areas. Yunnan ethnic minority areas must coordinate the relationship between economic development and ecological environmental protection, and promote the realization of green, coordinated and sustainable development. And strengthen the rectification of problems discovered by environmental protection inspectors, so as to realize the "win-win" of economic development and ecological security.

\section{References}

Alexander, D. E. (2013). Resilience and disaster risk reduction: An etymological journey. Nature Hazards Earth System Science, 13(11), 2707-2716. https://doi.org/10.5194/nhess-13-2707-2013

Cai, J. M., Guo, H., \& Wang, D. Y. (2012). Review on the resilient city research overseas. Progress in Geography, 31(10), 1245-1255.

Chen, Y. M., \& Li, K. C. (2017). Overseas studies progress and practice exploration on resilient city-Based on the perspective of public administration. Chinese Public Administration, 1, 137-143.

Hill, E. (2012). Economic shock and regional economic resilience. Urban and Regional policy and Its Effects, 4, 23-35.

Holling, C. S. (1973). Resilience and stability of ecological systems. Annual Review Ecological System, 4, 1-23. https://doi.org/10.1146/annurev.es.04.110173.000245

$\mathrm{Hu}, \mathrm{Z}$. J. (2015). Research on degree of the coordinated development between financing services and economic development in China. Journal of Central University of Finance \& Economics, 3, 34-40.

Liu, J. Y., \& Zeng, Z. P. (2014). The construction of flexible city evaluation index system and its empirical research. E-Government, 3, 82-88.

Liu, Y. T., \& Zhao, S. (2019). Research on the coupling and coordination relationship between urbanization and ecological environment in Beijing-Tianjin-Hebei city cluster. Jiangsu Agricultural Sciences, 47(17), 330-333. https://doi.org/10.25236/IJFS.2019.010105.

Man, S. (2019). Measuring urban economic resilience in northeast China. [Master's. thesis, Harbin Normal University, Harbin, Heilongiiang].

Nie, X. H. (2017). A review of research on Yunnan natural disasters in recent 30 years. Journal of Wenshan University, 30(10), 13-20. 
Pimm, S. L. (1984). The complexity and stability of ecosystems. Nature, 307, 321-326. https://doi.org/10.1038/307321a0

Sun, Y., Zhang, L. C., \& Yao, S. M. (2017). The resilience evaluation of Yangtze River Delta cities from the perspective of social ecosystem. China Population Resources and Environment, 27(8), 151158.

Tong, C. J. (2013). Evaluation and mode selection of coordinated development of urban and rural economy. Science Press.

Xu, Z. Q., Wang, Y. N., Guo, J. X., \& Pan, L. (2014). Strategic thinking on promoting urban planning and construction of the resilience cities in China. Urban Development Studies, 21(5), 79-84.

Zhang, M. D., \& Feng, X. Q. (2018). Comprehensive evaluation of resilience of Chinese cities. Urban Problems, 10, 27-36.

Zhou, Z. Z. (2019). Research on the coupling and coordination development of urbanization and ecological environment in Yangtze River Economic Belt. Journal of Harbin University of Commerce, 6, 30-41. 